\title{
Ciudadanía y cuidados; apuntes para una política feminista democrática
}

\section{Citizenship and care; notes for a democratic feminist politic}

\author{
TOMEU SALES GELABERT
}

\begin{abstract}
Resumen: El presente texto aborda la relación entre la ciudadanía y los «cuidados» desde de una perspectiva feminista. En este sentido, la consideración, valoración e integración del cuidado como actividad, valor y relación política supone la necesaria rearticulación de la ciudadanía como identidad socio-política. El intento por elaborar crítica y propositivamente una ciudadanía inclusiva desde la perspectiva de género, parte primero por la deconstrucción del discurso de la naturalización femenina del cuidado, y por otro lado, resituar y valorar el cuidado como actividad y valor que garantice el bienestar necesario para alcanzar una ciudadanía plena.

Palabras clave: Ciudadanía, cuidado, feminismo, género, justicia, política del cuidado.
\end{abstract}

\begin{abstract}
This paper tries to show the relationship between citizenship and the «care», all from a feminism perspective. In this sense, the consideration, valuation and integration of the care, how an activity, value and political relationship mean the necessary articulation again of citizenship as a social and political identity. Someone attempt to make a critic of an inclusive citizenship from gender point of view, has to go to the deconstruction of discourse of care's female naturalization, and the other hand, to place again and value the care as an activity and value that it guarantee the necessary welfare to achieve a full citizenship.
\end{abstract}

Key words: Citizenship, care, feminism, gender, justice, politics of care.

\section{Límites de la ciudadanía moderna}

El concepto de «ciudadanía» ha estado presente a lo largo de la historia y reflexión de la filosofía política. La ciudadanía moderna se articula en torno a las críticas al origen divino del poder de los reyes, utilizando la metáfora del contrato social como instrumento crítico. Dicha idea se sustenta sobre la existencia de un «estado de naturaleza» pre-político y la aparición de

Fecha de recepción: 31/12/2013. Fecha de aceptación: 19/11/2014.

* tomeu.sales@uib.es Profesor Ayudante Doctor de la Universitat de les Illes Balears. Departament de Filosofia $i$ Treball social. Licenciado en Filosofía y Doctor en Humanidades y Ciencias Sociales por la Universidad de les Illes Balears. Miembro del grupo de Investigación: Política, Trabajo y sostenibilidad, de la UIB. Entre sus últimas publicaciones cabe destacar: «Feminismo, democracia y ciudadanía; de la crítica a la democracia patriarcal a la política democrática radical», en Astrolabio. Revista Internacional de Filosofía, n ${ }^{\circ}$ 15, 2013, pp. $72-79$. «Los límites de la ciudadanía europea: Estado-nación, globalización y Unión Europea», en RIPS. Revista de Investigaciones políticas y sociológicas, Vol. 8, n², 2009, pp. 97-114. Este trabajo se enmarca dentro del proyecto de investigación titulado: La Europa de las mujeres. Construcción política y nuevas formas de ciudadanía. Proyecto financiado por el Ministerio de Economía y Competitividad con referencia FFI2012-33557. 
la «sociedad civil» y el «poder político» como concertación «convencional» del poder. Los teóricos del contrato social, desde diferentes posiciones antropológicas e ideológicas, parten de la idea de la existencia de «derechos naturales» (iusnaturalismo), individuales y pre-políticos. Derechos protegidos y desarrollados por el poder político. El sujeto de estos derechos es el ciudadano, entendido éste como un sujeto autónomo, independiente y racional. Cómo se interpreten estos conceptos dará lugar a una determinada concepción de la ciudadanía ${ }^{1}$.

Desde una aproximación sincrónica y pragmática, la ciudadanía moderna se entiende como una forma «de presencia y relación de los individuos con la sociedad en tanto que organizada políticamente (en tanto que ciudad)» (Peña, 2003, 216). Los elementos estructurales que integran el concepto de ciudadanía son: derechos, pertenencia y participación. En este orden de aparición en base a su valor en la modernidad liberal-capitalista. La ciudadanía moderna como identidad socio-política aparece al mismo tiempo que la constitución del modo de producción capitalista. Son procesos que se refuerzan mutuamente. El burgués representa el máximo exponente del ciudadano moderno. Uno de los primeros y básicos derechos de la ciudadanía moderna será el de la propiedad, tanto de bienes como de su propia persona. De ahí se derivará consecuentemente el resto de los conocidos como «derechos civiles» (Fraser y Gordon, 1992, 70). Así, la interpretación del quién de la ciudadanía varía históricamente².

Una ciudadanía que se articula en torno a una nueva concepción de la comunidad política, modernamente entendida como Estado-nación, en cuyas instituciones políticas los ciudadanos participan de forma instrumental. Aunque ha habido formas diferentes de interpretación de la ciudadanía moderna, la hegemónica ha sido la liberal-individualista-propietarista. Por ello, los elementos de la pertenencia y la participación política de la ciudadanía se han subordinado a los derechos civiles, sobre todo al derecho de la propiedad privada ${ }^{3}$.

1 Cabe recordar aquí la acusación de androcentrismo que lleva a cabo C. Pateman en su famosa obra El contrato sexual de la teoría del contrato social liberal. Pateman sostiene que previo al contrato social existe un contrato sexual implícito que asumen todos los teóricos contractualistas modernos. Así, Pateman afirma que: «La diferencia sexual es una diferencia política, la diferencia sexual es la diferencia entre libertad y sujeción. Las mujeres no son parte del contrato originario a través del cual los hombres transforman su libertad natural en la seguridad de la libertad civil. Las mujeres son el objeto del contrato. El contrato (sexual) es el vehículo mediante el cual los hombres transforman su derecho natural sobre la mujer en la seguridad del derecho civil patriarcal» (Pateman, 1995, 15). El contrato sexual implícito al contrato social de forma acrítica, hace que aunque la sociedad contractual liberal se sustente sobre la idea de la libertad de los individuos contratantes, no esté más que sustentada sobre la dominación de la mitad de la sociedad; las mujeres. Así, la sociedad liberal es patriarcal, al no cuestionar el contrato originario o sexual previo al contrato que funda la sociedad civil. En este texto nos centraremos en otras críticas a la sociedad liberal moderna capitalista, ya que el objetivo es mostrar como la concepción de la sociedad y los individuos ha invisibilizado, marginado y generizado el cuidado. Por tanto dejaremos de lado la valiosísima aportación crítica de Pateman.

2 Si se entiende que el ciudadano es aquel que posee bienes y su propia persona, todos aquellos que no posean ni bienes ni su propia persona no pueden ser definidos como ciudadanos. De esta manera, ni las mujeres excluidas de las formas de propiedad y tenencia de bienes y por tanto de su propia persona («co-protegidas» es la categoría que les asigna Kant), ni los trabajadores por cuenta ajena, ni los pobres entran dentro de la categoría de ciudadanos. Son excluidos de la ciudadanía.

3 El capitalismo y el capitalista entiende tanto el Estado, la nación como la participación política de forma instrumental-funcional. El Estado moderno, sobre todo en sus inicios es un Estado de clases en el sentido marxista del término. Sirve a los intereses de la clase propietarista. Sólo así se pueden entender fenómenos históricos como el proteccionismo, el imperialismo o la globalización neoliberal. Del lado de la participación, la consolidación moderna de las formas de democracia representativas en detrimento de formas de democracia participativa y asamblearia han tendido a reducir hasta la nimiedad los mecanismos de participación políticas. Reducidos prácticamente a puros actos simbólico-rituales. 
Más allá de esta construcción e interpretación histórica de la ciudadanía moderna, el concepto en sí tiene un significado crítico-emancipador: «una palabra que condenaba la tiranía y la jerarquía social, a la vez que afirmaba la autonomía y la igualdad (...). Tiene tanta dignidad que rara vez aparece en el lenguaje coloquial (...). No se encuentran usos peyorativos. Es una palabra humanista importante, monumental» (Fraser y Gordon, 1992, 65-66). En este sentido, los diferentes movimientos críticos-emancipadores modernos han traducido y siguen traduciendo sus reclamaciones y reivindicaciones en clave de ciudadanía. Se reclaman nuevos derechos de ciudadanía, una ciudadanía plena, activa, crítica, saludable, sensible con la diferencia, etc. El concepto de «ciudadanía» en el imaginario social moderno hace referencia a la crítica social desde la perspectiva del igualitarismo social y la libertad.

El feminismo como movimiento emancipador en su doble condición teórica y práctica, es decir, como teoría feminista y como movimiento social se ha centrado en la crítica a la ciudadanía moderna por ser patriarcal (Agra, 2002, 130). En este sentido, el feminismo como movimiento moderno nace con la razón ilustrada, crítica con las tradiciones y los diferentes intentos de naturalizar las desigualdades sociales. Es un discurso crítico-ilustrado que critica las propuestas ilustradas desde sus propias bases epistemológicas y normativas. Por tanto, el feminismo nace a la par con la instauración de la ciudadanía y la democracia moderna, inscribiéndose como discurso crítico, contra-hegemónico, pero al mismo tiempo universalista y emancipador (Amorós, 2008b, 46).

El feminismo formula sus reivindicaciones a partir de la teoría de la ciudadanía y la teoría democrática. Los momentos de este proceso son dos: el de la crítica al androcentrismo de la concepción de la ciudadanía moderna y la propuesta de una ciudadanía inclusiva e igualitaria, por tanto democrática, desde la perspectiva de género. En los últimos años, tanto las críticas a la concepción de la ciudadanía moderna como las propuestas alternativas han sido amplias y variadas (Agra, 2002). Centrando el debate en los términos que nos interesa, prestaremos atención a dos de las críticas al androcentrismo de la concepción de la ciudanía moderna, para luego pasar a analizar y desarrollar la tesis central del presente texto de qué una ciudadanía crítica con las diferencias de género debe abordar e integrar las cuestiones sobre el cuidado de los demás. Se trata de un proceso de dos caras, una deconstructiva y la otra constructiva.

\section{La independencia y el individualismo-posesivo de la ciudadanía moderna}

Desde la deconstrucción y en la dirección del cuidado como dimensión básica de la ciudadanía sensible con las diferencias de género se destacan dos grandes críticas al androcentrismo de la ciudadanía moderna. La primera crítica se basa en la idea de qué la ciudadanía moderna parte de una ontología social individualista y atomista, tanto epistemológicamente como normativamente. La segunda crítica se basa en la idea de qué la ciudadanía moderna parte de una concepción de las relaciones sociales reduccionista, entendidas como relaciones interesadas y egoístas. Las dos críticas muestran que la presencia que encarna el ciudadano moderno es un individuo individualista, egoísta, parapetado bajo una racionalidad instrumental-calculista. Para desarrollar la primera crítica se recuperará el debate que inicia C. Gilligan a finales de los 70 y principios de los 80 con la propuesta de la «ética de cuidado» de la mano de S. Benhabib. La segunda cuestión se desarrollará a partir del análisis de la ciudadanía civil que hace Nancy Fraser y Linda Gordon en la «cultura política norteamericana» como antitética de la ciudadanía social. 
A finales de la década de los 70 L. Kohlberg y su ayudante C. Gilligan trabajaban en una teoría ontogenética de la moral. Kohlberg llegó a la conclusión, luego matizada y reformulada, que las mujeres eran incapaces de llegar al estadio 6 de desarrollo de la consciencia moral; es decir, las mujeres tenían un desarrollo moral inferior a los varones, ya que eran incapaces de desarrollar una consciencia moral orientada por principios éticos universalistas, formales y abstractos. Gilligan reaccionó proponiendo una reinterpretación de los resultados empíricos. Según Gilligan no se trataba de qué las mujeres tuviesen un desarrollo moral inferior al de los varones, sino que simplemente tenían un desarrollo diferente, que ella llamaba «contextualismo postconvencional» frente al «formalismo postconvencional» del desarrollo moral de los varones (Benhabib, 2006, 172). Gilligan re-articuló su propuesta en su obra A Different Voice en 1982, obra que inicia la discusión y diferenciación entre por una parte una «ética de la justicia» y por otra parte una «ética del cuidado». Esta última más interdependiente, contextual y emotiva, «propia de las mujeres». Según Gilligan las mujeres juzgan moralmente de forma diferente a los varones. Su razonamiento moral es más contextual, narrativo y centrado en detalles relacionales ${ }^{4}$.

Gilligan no intentó naturalizar el debate, sino simplemente llegó a la conclusión de que la socialización diferencial en razón de género producía formas diferentes de abordar los problemas morales. El razonamiento de Gilligan era psico-social, no biologicista. Pero además, expuso un prejuicio moral moderno hasta el momento incuestionado. La idea de que el sujeto moral que toma decisiones morales de forma abstracta y formal es un ser autónomo, entendiendo la autonomía moral como independencia. Este prejuicio sobre el que se articula el imaginario moral moderno hace que la teoría moral se centre en cómo se puede proteger la independencia de este sujeto, antes que preguntarse en el cómo se constituye este sujeto. Se obra la separación entre la esfera de la justicia y la esfera de la vida buena (Benhabib, 2006, 177). Según la versión hegemónica, la teoría moral se centra en las cuestiones de justicia, para dejar a la libre disposición de la esfera privada las cuestiones de la vida buena. Las cuestiones morales versan así sobre procedimientos para salvaguardar la independencia de los sujetos morales, tanto del poder político como de los «otros» sujetos independientes.

La teoría moral moderna parte y se basa en el prejuicio acrítico de la existencia de un sujeto moral como sujeto independiente que toma decisiones racionales sobre los otros, pensado que éstos son como el yo mismo. Las cuestiones del cuidado, la responsabilidad, la atención, la sexualidad, el amor, etc., pasan a ser cuestiones amorales, individuales y privadas ${ }^{5}$. Las preocupaciones por cómo se constituye este sujeto autónomo-independiente dejan de ser morales. Se parte de la ficción del sujeto moral como sujeto adulto, racional e interesado. La figura que hay

4 C. Gilligan afirma que «El concepto de los derechos cambió a las mujeres sus concepciones de ellas mismas, permitiendo verse más fuertes y considerar directamente sus propias necesidades. Cuando dicha afirmación ya no parece peligrosa, el concepto de las relaciones cambia desde un vínculo de continuar la dependencia a la dinámica de la interdependencia. Así, la noción de cuidado (care) se expande desde un mandato paralizante de no dañar a los otros a un mandato a actuar responsablemente hacia uno mismo y los otros, y así mantener la conexión. La consciencia de las relaciones humanas se convierte en fundamental para la comprensión moral, uniendo el corazón y la visión, en una ética que vincula la actividad del corazón con la del cuidado (Gilligan, 2003, 149). Traducción propia.

5 El universalismo moral moderno abre la puerta, como mostró la crítica del feminismo de la segunda ola al relativismo moral y al todo vale de la esfera privada. Es decir, abre la puerta a cierta inmoralidad fuera de la esfera de la pública de la justicia. 
detrás de este sujeto narcisista que ve el mundo desde su mismidad es el varón-burgués. Los trabajos de cuidado no sólo se invisibilizan y se les imputa a los sujetos no autónomos-independientes (niños, mujeres, hombres pobres, trabajadores ${ }^{6}$ etc.) sino que además se les sustrae de su consideración moral, abriendo un ámbito de subordinación y brutalidad justificado e ilimitado.

Contra la versión moderna hegemónica de la teoría moral, la moralización y el énfasis en la esfera de los cuidados no conllevan el abandono de dicho paradigma moral basado en la centralidad de la autonomía moral, sino simplemente su consolidación por la vía de la reincorporación de procesos y dimensiones hasta estos momentos olvidados e ignorados. Procesos que han sido puestos de manifiesto por la crítica feminista a la filosofía moral moderna. Dichas críticas producen una nueva concepción más amplia y compleja del sujeto moral, entendido éste como un sujeto receptor de cuidado y que cuida. El cuidado y la responsabilidad se convierten en valores morales centrales al mismo tiempo que el valor de la autonomía. Esta «inclusión por ampliación» no sólo muestra la limitación del pensamiento moral moderno, sino que permite superar la absurda discusión binaria y dicotómica desarrollada a lo largo de la década de los 90 entre por una parte una «ética del cuidado» y una «ética de la justicia». La crítica feminista a la teoría moral moderna muestra que no puede haber justicia sin cuidado, ni cuidado sin justicia.

Pasando a la segunda cuestión apuntada más arriba, la ciudadanía moderna al ser una ciudadanía capitalista se estructura en torno a relaciones o interacciones interesadas entre individuos-propietarios, obscureciendo o eliminando formas alternativas de interacción social. Este proceso tiene graves consecuencias a la hora de categorizar el trabajo del cuidado y muestra como éste ha sido marginado, desprestigiado, generizado e invisibilizado ${ }^{7}$.

Nancy Fraser y Linda Gordon analizaron la «cultura política norteamericana» a raíz de la discusión crítica con la tesis optimista de Th. Marshall (Ciudadanía y clase social, 1949) de que el desarrollo último y necesario de la ciudadanía moderna es la constitución de una «ciudadanía social», entendida como «un derecho a compartir todo el patrimonio social y a vivir la vida de un ser civilizado según los patrones que prevalezcan en la sociedad» (Fraser y Gordon, 1992, 68). Para Fraser y Gordon en la sociedad americana, modelo y prototipo de sociedad liberal, la constitución de la ciudadanía civil sobre la idea de la propiedad privada del individuo burgués imposibilita el desarrollo de una ciudadanía social plena, entendida como la entiende Marshall. Fraser y Gordon identifican una contradicción esencial en la ciudadanía moderna capitalista, que según las autoras se hace más fuerte en la «cultura

6 En este sentido algunas autoras como J. Toronto habla de la asociación del trabajo de cuidados no a las mujeres sino a los subordinados (Comins, 2009: 47). Las mujeres y otros colectivos subordinados serían los encargados de llevar a término los trabajos viles y embrutecedores del cuidado.

7 En referencia a la generización del trabajo de los cuidados María Ángeles Duran aporta un interesante perfil social del cuidador «que constituye el soporte básico del Estado de Bienestar español: es mujer, de edad intermedia entre 50 y 60 años, no tiene empleo, dedica más de 40 horas semanales al cuidado del dependiente, tiene dificultades económicas, asume casi en exclusiva el cuidado del dependiente, lo hace durante largos años, padece patologías múltiples y especialmente cansancio, carencia y trastornos del sueño, dolores de espalda, y frecuentemente depresión, y por último, siente miedo respecto al futuro» (Duran, 2006, 59). Respecto a la invisibilización, cabe recordar como hace la misma autora en otro texto la dificultad de cuantificar el trabajo no mercantil, en concreto sostiene la autora, «de todas las actividades, la más difícil de cuantificar es, sin duda, la del «cuidado», sea de objetos o personas. El «cuidado» es más una responsabilidad general que una actividad específica y rebasa cualquier posible desagregación (...). El cuidado se asimila a las tareas de vigilancia, más medibles por el tiempo de incompatibilidad con otras actividades que por las tareas específicas desarrolladas» (Duran, 2000,12). 
política norteamericana». Esta contradicción gira entorno a la metáfora del «contrato» que dará paso a la diferenciación binaria y dicotómica entre relaciones contractuales y relaciones «caritativas», que categorizan la totalidad de las interacciones sociales ${ }^{8}$.

La ciudadanía civil aparece a finales del s. XVIII. Se desmorona el orden social feudal de relaciones y privilegios estáticos, apareciendo un nuevo orden social individualista y capitalista. No hay relaciones sociales previas a los individuos. Estos tienen «derechos naturales» previos a cualquier relación; derechos que se estructuran en base al modelo del derecho a la propiedad. El ciudadano por tanto es aquel individuo varón y propietario que vive en la ciudad y goza de una serie de libertades, conceptualizadas como derechos. Aparece una nueva esfera de interacción social, la «sociedad civil». Esfera donde el individuo interactúa de forma interesada y concertada con otros individuos, para desplegar, proteger y expandir su propia individualidad y propiedades. Surge la metáfora del «contrato» como forma de categorizar estas nuevas formas de interacciones sociales. Un nuevo orden social asociado a una nueva ontología social individualista y propietarista que dará paso a un nuevo imaginario social, donde el «contrato» interesado y entre iguales se transformará en el prototipo de relación e interacción social. La metáfora del contracto se convierte en una ficción fundante y estructurante de las nuevas formas de relación social.

Este nuevo orden social individualista y propietarista que se abre con la ciudadanía civil parte y produce nuevas y radicales formas de exclusión social. Las mujeres, los pobres y los «esclavos», no sólo quedan excluidos de la ciudadanía civil al no ser propietarios, sino que o bien son asociados a la propiedad de los ciudadanos (caso de la esclavitud moderna) o bien son entendidos como protegidos (el caso de las mujeres o los pobres bajo la «protección» de las leyes de beneficencia social). Por tanto, la nueva esfera social del intercambio contractual de la sociedad civil, no era extensiva a toda la sociedad, sino solamente a una parte de ella. Una esfera basada en nuevas formas de exclusión y de dominación social (Fraser y Gordon, 1992, 71). El modelo del ciudadano era el varón, blanco y propietario. La ciudadanía civil no supuso por tanto un aumento significativo del estatus de todos los habitantes de las ciudades, sino el de unos cuantos en detrimento de otros que vieron disminuidos sus estatus sociales anteriores ${ }^{9}$.

La constitución de la esfera de la «sociedad civil contractual» se desarrolló al mismo tiempo que apareció la esfera «privada-familiar-íntima». La transformación del ámbito de producción como ámbito de interacción contractual entre iguales, tuvo como consecuencia la transformación de la familia, que en el orden social anterior había funcionado como unidad de producción. Apareció una «nueva disyuntiva ideológica» entre dos esferas diferenciadas de interacción social: la esfera de la sociedad civil, del contrato entre iguales, y la esfera de la intimidad, de las relaciones regidas, no por el contrato, sino por los sentimientos (Carrasco, Borderías y Torns, $2011,19)$. Una nueva esfera de desigualdad social que se naturalizó bajo el discurso de los sentimientos, no regidos por la interacción equitativa. Si la esfera de la «sociedad civil» era el ámbito de la interacción entre los ciudadanos iguales y propietarios, la esfera «familiar-doméstica»se convirtió en el ámbito de la subordinación y la desigualdad, del intercambio sin contrapresta-

8 Dicha tesis invalidaría la versión socialdemócrata de la posibilidad de la convivencia del sistema social de producción capitalista con un Estado democrático y de bienestar (aunque las autoras no se muestran tan categóricas al respecto).

9 Como es el caso de las mujeres, que gozaban de un rol social y productivo mucho más significativo en las sociedades pre-capitalistas. 
ción; el ámbito de los excluidos de la ciudadanía, el ámbito de las mujeres, esclavos, niños, dependientes, etc. La diferenciación moderna de las esferas sociales se generiza y se etnifica.

Con la ciudadanía moderna todas aquellas interacciones no contractualistas bien se definirán como interacciones doméstica regidas no por la razón interesada sino por los sentimientos desinteresados o bien se definirán como «caridad» ${ }^{10}$. Caridad que ensalza la reputación moral del donante y estigmatiza la del receptor. El ciudadano entendido como individuo-propietario se desentiende de cualquier compromiso y responsabilidad social con los otros, más allá de los compromisos familiares-privados. Limita las formas de interacción social a la interacción interesada. La caridad no alumbra otra forma alternativa de interacción desinteresada y solidaria, sino que se convierte en la forma bastarda y peyorativa de las relaciones hegemónicas contractuales. Los derechos sociales, entendidos como derechos del disfrute del patrimonio común y el interés general en el bienestar de todos, no tienen cabida en el esquema contracto-caridad de la ciudadanía moderna-capitalista.

En cuanto al tema de los trabajos del cuidado se puede ver claramente que la ciudadanía moderna, basada como se ha visto anteriormente en una concepción moral de la autonomía concebida como independencia respecto a los otros, y estructurada entorno al individuopropietarista que entiende la totalidad de las relaciones sociales como relaciones contractuales, no permite visibilizar y valorar la trascendencia del cuidado y los cuidados en la constitución de los ciudadanos activos y plenos. La perspectiva del cuidado necesita partir de una nueva ontología social, menos individualista y más interdependiente, menos independiente y más solidaria, que supere la concepción moderna de los cuidados bien como tarea doméstica, familiar, íntima, no productiva, ni valiosa, ilimitada, basada en la ideología de la naturalización de los sentimientos de compromiso, bien como acciones caritativas, altamente estigmatizantes, voluntaristas y sin ningún tipo de responsabilidad social más allá de la responsabilidad individual o familiar. El cuidado y el trabajo de los cuidados han de ser entendidos como parte de un derecho de ciudadanía social, entendido de forma más amplia, como el compromiso social en el bienestar y el desarrollo de todos los integrantes de la sociedad. Esta nueva perspectiva del cuidado y del trabajo del cuidado como derecho de ciudadanía social necesariamente ha de desprenderse de los elementos limitantes individualistas-propietaristas de la ciudadanía moderna capitalista, ya que sino su implementación será imposible. No cabe en el marco reducido y estrecho de la modernidad capitalista e individualista.

\section{Hacia una concepción integrada y crítica del cuidado}

La preocupación en las ciencias sociales por la «cuestión de los cuidados» apareció hace unos cuarenta años, de la mano del feminismo de la segunda ola en el ámbito europeo. El cuidado ha sido abordado en las ciencias sociales y más en concreto en la sociología desde tres posiciones diferentes: como un trabajo reproductivo necesario y diferente al trabajo productivo (Silvia Federici y Mariarosa Dalla Costa), como catalizador de un conjunto de emociones y valores que acompañan a cierto tipo de actividad humana (C. Gilligan), o bien

10 «Cualquier interacción que no apareciera como contractual ni familiar se concebía ahora como unilateral y enteramente voluntaria, sin comportar derecho ni responsabilidad alguna. Así, la hegemonía del contracto contribuyó a generar una concepción específicamente moderna de la "caridad" como alternativa complementaria del mismo» (Fraser y Gordon, 1992, 76). 
como un derecho de ciudadanía. Las tres perspectivas tienen en común el partir de una crítica feminista a la sociedad moderna, aunque se diferencian en base al momento histórico y el ámbito geográfico, que determina tanto una forma de feminismo como de observar y analizar el cuidado. Por tanto, conceptualmente es difícil hallar un concepto unitario de «cuidado», ya que es un término cuyo significado varía tanto histórica, geográfica como académicamente ${ }^{11}$.

Siendo conscientes de las limitaciones conceptuales del término «cuidado» se puede buscar un concepto genérico y unitario del cuidado. En la década de los noventa J. Toronto y B. Fisher aportaron una definición del mismo. Para ellas el cuidado es: «una actividad de especie que incluye todo aquello que hacemos para mantener, continuar y reparar nuestro "mundo" de tal forma que podamos vivir en él lo mejor posible. Ese mundo incluye nuestros cuerpos, nuestros seres y nuestro entorno, todo lo cual buscamos para entretejerlo en una red compleja que sustenta la vida» (Toronto, 2004, 234). Desde esta perspectiva, el cuidado pasa a ser una dimensión o actividad humana más, que nos sitúa en relación a los otros y a la naturaleza. Una «actividad de especie», como dicen las autoras. Una actividad que humaniza, y nos constituye propiamente como humanos. Una actividad desgenerizada, aunque histórica y socialmente se haya generizado. Su generización implica la alienación y la deshumanización tanto del género al que se encomienda el cuidado ${ }^{12}$ como del género al que se considera receptor puro del cuidado ${ }^{13}$. Se trata de una definición sumamente genérica y abstracta del cuidado que se situaría en el plano de una nueva ontología social, no en el plano metafísico. Se habla de una actividad, una praxis propia del ser humano, que se estructura social e históricamente de forma diferencial. De ahí, la importancia del análisis histórico para abordar las cuestiones del cuidado y sobre todo de su generización ${ }^{14}$.

Según la definición de Toronto y Fisher, el cuidado es una actividad que incluye tres fases: preocuparse, atender y cuidar. «Preocuparse implica reconocer la necesidad de cuidar.

11 Distintas disciplinas abordan de forma diferencial el tema del cuidado. En la actualidad el cuidado es analizado desde las ciencias sociales, la sociología, teoría política, economía, historia de la familia, de la infancia, pasando por la medicina, la enfermería y hasta llegando a un concepto ontológico-metafísico propio de la antropología filosófica (S. Kierkegaard, Heidegger, Scheler...). Aquí se ha centrado el debate en torno al concepto en el ámbito de las ciencias sociales. Resaltar la importancia que tiene la reflexión del cuidado en el ámbito del ecofeminismo. Sería interesante exponer dicho concepto, ya que varía tanto dependiendo de la época como de las diferentes corrientes que se pueden distinguir en el seno de dicha perspectiva teórica y movimiento social, aunque la falta de espacio hace imposible dicha tarea.

12 Hay diferencias de género tanto en cuanto a los proveedores del cuidado como en la forma de la provisión. Como apunta María Ángeles Duran «Las mujeres realizan esta actividad más frecuentemente, pero lo hacen simultaneándola con otras actividades domésticas (...). Dicho de otro modo, densifican su trabajo no remunerado. Los varones ejercen esta actividad menos frecuentemente, pero cuando lo hacen tienden a hacerlo de un modo menos superpuesto a otras actividades, entre otras cosas porque es incompatible con los trabajos remunerados fuera del hogar a los que ellos suelen dedicarse en la edad madura» (Duran, 2006, 65).

13 En este punto, se pueden pensar que se habla de un concepto de cuidado sumamente abstracto, cuasi metafísico. Pero es necesario de cara a la reconstrucción del cuidado como actividad valorizada y propia de una ciudadanía inclusiva desde la perspectiva de género.

14 La «ideología de la domesticidad» que enclaustra a la mujer en el ámbito doméstico-privado aparece como un subproducto de una serie de cambios socio-productivos a raíz de la Revolución industrial, la familia, la urbanización, transformaciones demográficas, higiénicas, etc. Por tanto, difícilmente se puede hablar de un universal antropológico-social, sino que se trata de un producto social e históricamente determinado. En el estudio de los «trabajos de cuidados» la microhistoria es fundamental para no cometer errores conceptuales. Entendiendo por microhistoria, no la historia político-institucional sino la historia de la evolución de la familia, del concepto de infancia, del concepto de vejez, salud pública etc. 
Atender implica asumir la responsabilidad del trabajo que hay que hacer para cuidar. Cuidar consiste en realizar el verdadero trabajo y recibir los cuidados, es la respuesta de quien recibe los cuidados» (Toronto, 2004, 234). Además, como defienden las autoras, podemos diferenciar los tipos de cuidado en base a las instituciones encargadas de proveerlos; los cuidados pueden ser proveídos en el hogar, por el mercado o por la «sociedad civil». Se puede añadir desde el ámbito europeo, que también el Estado provee servicios y políticas encaminadas al cuidado de los ciudadanos. Más allá del debate sobre la provisión, las tres fases del cuidado que proponen las autoras enmarcan el tema del cuidado de una forma mucho más holística. El cuidado o trabajo de cuidados no se limita a la recepción y/o provisión de los mismos, sino que también hace referencia a la intencionalidad y la responsabilidad de los cuidados. Además, propone una concepción alternativa de los cuidados que rompe con la concepción socialmente hegemónica de los mismos que los entiende de forma reduccionista y unilateral. Dicha concepción no sólo estigmatiza a los receptores de cuidados (niños, ancianos, personas dependientes, etc.), sino que además no atiende a la necesidad de recibir cuidados que tienen los cuidadores.

La concepción holística del cuidado que propone Toronto puede ser complementada con la concepción que propone C. Thomas en 1993. Para Thomas hay siete dimensiones a tener en cuenta cuando se habla del trabajo de cuidados: la identidad social de la persona cuidadora, la identidad social de la persona receptora de cuidados, las relaciones interpersonales entre la persona cuidadora y la receptora de cuidados, la naturaleza de los cuidados, el dominio social en el cual se localiza la relación de cuidados, el carácter económico de la relación de cuidados (si existe o no) y el marco institucional en el cual se prestan los cuidados (Thomas, 2011, 149-151). Thomas intenta deconstruir y hacer empíricamente utilizable el concepto de «cuidar». El cuidar o trabajo de cuidados es una relación social entre el cuidador y el receptor de los cuidados, los cuales establecen vínculos especiales entre ellos, que determinan la naturaleza del cuidar (si implica algún tipo de emoción y/o sentimiento), el ámbito social en que se llevan a cabo los cuidados (público/privado, mercado/Estado, familia/ amigos), si hay mediación pecunia entre el cuidador y el receptor del cuidado, además de si hay un marco jurídico-institucional que regle las relaciones del cuidar (derechos, obligaciones, procedimientos...). Al tratarse el cuidado como una relación social, ésta estará mediatizada y condicionada social e históricamente, abriendo la puerta a formas plurales y diversas de cuidar y ser cuidado.

\section{Enfoque agonístico del cuidar}

El cuidado como praxis humana que establece formas diferenciales de relaciones sociales no está exento de relaciones de poder ${ }^{15}$. En este sentido, se puede aplicar al estudio del cuidado o trabajo de cuidados el enfoque del «pluralismo agonístico» de Ch. Mouffe. Un enfoque socio-político de las relaciones sociales. Mouffe sostiene que las relaciones sociales siempre son conflictivas. Esta conflictividad social funda «lo político» y se articula en torno a la relación «amigo-enemigo». «La política», en cambio es el marco institucional que

15 Éstas son relaciones entre uno o más individuos, en que unos imponen ciertas condiciones, visiones y limitaciones a otros. Una concepción weberiana del poder, no como concertación, sino como relación de dominación. Aunque como señalara Weber, la dominación no siempre es directa, sino que puede llevarse a cabo a través de formas indirectas como la ideología, el carisma, el estatus, etc. A nivel empírico, María Ángeles Duran ha señalado las condiciones y la carga que representa el cuidado para los cuidadores (Duran, 2000, 26). 
desactiva parcialmente el conflicto antagonístico, convirtiéndolo en agonal. Las relaciones «amigo-enemigo» se convierten en relaciones «amigo-adversario» (Mouffe, 1999, 22).

Los cuidados entendidos como actividad de especie y como relaciones sociales son intrínsecamente políticos. Se establecen y fundan sobre una base de conflictividad entre el cuidador y el receptor de los cuidados. Se habla de conflictividad en tanto que pérdida de autonomía de uno respecto al otro, o de ambos, además de los diferentes conflictos de lealtades que esconden. Relación contingente, ya que el cuidador puede pasar a ser receptor de cuidados y el receptor de cuidados ser al mismo tiempo cuidador en otras fases del cuidar ${ }^{16}$. Esta conflictividad funda la relación entre el cuidador y el receptor de cuidados, que queda desactivada por el marco institucional en que se dé. Este marco institucional que desactiva el conflicto inherente a toda relación basada en el cuidar, tiene siempre una dimensión material y otra ideológica. Los cuidados son relaciones materiales que pueden ubicarse en ámbitos sociales diferentes, como pueden ser la familia, el mercado, la sociedad civil y el Estado. Además, los cuidados se llevan a término regidos por códigos de conducta legales-morales, que tienen la función social de legitimarlos.

Para Mouffe los principios de libertad e igualdad de la democracia son los que posibilitan el paso de «lo político» a «la política» y la desactivación de la relación «amigo-enemigo». Aparece un amplio y variado espacio de conflictividad agonal ${ }^{17}$ entorno a la interpretación de los principios de libertad e igualdad por parte de varios agentes sociales. Interpretaciones que adoptan las diferentes formas de reivindicaciones sociales. La democracia, entendida como la política de la igualdad y la libertad posibilita tanto el pluralismo como el antagonismo ${ }^{18}$. Así, la desactivación de la conflictividad inherente al cuidar sólo puede venir de la institucionalización de dicha relación a partir de los principios de la libertad e igualdad, propios de la democracia. Dichos principios abren paso a una ciudadanía, entendida por Mouffe como «una forma de identidad política que consiste en la identificación con los principios de la democracia moderna pluralista, es decir, en la afirmación de la libertad y la igualdad para todos» (Mouffe, 1999, 120). La ciudadanía es una identidad política amplía y común a todos aquellos agentes sociales y sujetos que aceptan los principios de la democracia pluralista, es decir la libertad y la igualdad. La ciudadanía y la democracia desactivan la conflictividad social por la vía de la politización e institucionalización del conflicto a partir de los principios de libertad e igualdad.

Adoptando el modelo del pluralismo agonístico de Mouffe, se puede hablar de «una política del cuidar», entendida como el marco institucional que desactiva la dimensión conflictiva-agonística del cuidar. Este marco sólo perdurará si se basa en la democracia y sus principios básicos: la libertad y la igualdad. Dicha política del cuidar posibilita la «ciudadanía del cuidado», considerada como la identidad política que permite la identificación del cuidar y los cuidados a partir de la libertad y la igualdad.

16 Uno puede proveer cuidados a alguien, el cual atiende al que cuida preocupándose por su estado, dándole charla, etc., como se dijo la relación del cuidar no es unidireccional sino que es en la mayoría de casos bidimensional.

17 Agonal, no agonístico. El conflicto ya no se da entre amigo-enemigo, con la intención de exterminarse que tiene los dos. El conflicto agonal es el que se da entre amigo-adversario. El conflicto no desaparece, pero sí que éste está encauzado a través de una serie de procedimientos y pautas que ambos respectan. La pauta principal es el respeto mutuo y la aceptación del otro diferente.

18 En este punto, Mouffe se distancia de J. Habermas y de la teoría de la democracia deliberativa, al considerar que la democracia es posible en situaciones confrontación de valores y cosmovisiones diferentes (Mouffe, 2007, 20) 
A pesar de que la concepción de la inherente conflictividad social, la política como institucionalización de dicho conflicto y la democracia como institución basada en los principios de libertad e igualdad abren una nueva comprensión del cuidar y de los cuidados, el enfoque del pluralismo agonístico de Mouffe adolece de ciertas inconcreciones y generalizaciones que también afectan a su aplicación en el ámbito del cuidar. El problema central radica en la inconcreción de los principios de libertad e igualdad, tan importantes para la institucionalización política de lo político. Al basarse en una perspectiva posestructuralista su enfoque del pluralismo agonístico es incapaz de fundamentar dichos principios. Éstos existen a partir de sus concreciones prácticas por parte de los diferentes individuos. Esta perspectiva posestructuralista de las ciencias sociales conduce a un problema epistemológico y normativo sumamente importante en su intento por explicitar el contenido de los principios de libertad e igualdad que fundan, según ella la democracia.

Recapitulando, los cuidados entendidos como praxis y relaciones sociales son relaciones de poder; implican relaciones asimétricas entres dos o más individuos. Relaciones asimétricas que se pueden llamar a partir de la teoría social y política de Mouffe lo político del cuidado. Estas relaciones asimétricas se hacen sostenibles en el tiempo, se justifican y se reproducen socialmente en base a su institucionalización como política del cuidado. La política del cuidado institucionaliza tanto material como ideológicamente las relaciones agonales del cuidar, haciéndolas aceptables y duraderas. Por tanto, una ciudadanía democrática será aquella que permita formas alternativas de la política del cuidar. En este punto, aparece una pregunta moral fundamental: ¿Es justa toda relación de cuidado? Según la interpretación mouffeana, ésta lo será en tanto el conflicto radical que subyace en el cuidar se institucionalice a partir de los principios de libertad e igualdad. Pero éste no es un criterio normativo suficiente para discernir entre formas justas e injustas de cuidados. En este punto se necesita una teoría de la justicia social más vigorosa que la que se puede desprender del análisis de Mouffe.

\section{La justicia del cuidar}

Nancy Fraser trabaja desde los años ochenta en una teoría de la justicia que por un lado integre las condiciones sociales y materiales de la misma, y al mismo tiempo sea capaz de integrar diferentes reivindicaciones de justicia que provienen de ámbitos y contextos diferentes. Se trata de una concepción pragmática de la justicia. Fraser propone una concepción de la justica tridimensional y escalar.

La justicia se estructura por el principio normativo de la «paridad de la participación». Según este principio, «la justicia requiere disposiciones sociales que permitan que todos los miembros (adultos) de la sociedad interactúen unos con otros como pares» (Carbonero, M. A., Valdivieso, J., 2011, 332). Para que ello sea posible, según Fraser, se deben cumplir tres condiciones: una igual redistribución de los recursos materiales y patrones institucionales de valor cultural que expresen igual respeto para todos los participantes. Dicho de otra manera, la justicia entendida como la igualdad en la participación sólo es posible con cierta igualdad material y de patrones valorativos socio-culturales equitativos. Aparecen los conceptos de distribución y reconocimiento. La justicia requiere condiciones de cierta igualdad distributiva y de reconocimiento social. Amplía el concepto normativo de la justicia integrando elementos 
materiales y reivindicaciones críticas de diversos colectivos, como las feministas y los colectivos contra la segregación racial ${ }^{19}$. La tercera condición o disposición social de la justicia es la participación (Carbonero, M. A., Valdivieso, J., 2011, 291-308). Participación que más tarde llamará tercera dimensión de la justicia o dimensión política de la justicia, y que recibirá el nombre de representación. Fraser lo entiende en «un primer nivel, el que atañe al aspecto de establecimiento de límites de lo político, la representación es un asunto de pertenencia social. De lo que se discute aquí es de la inclusión en o de la exclusión de la comunidad de aquellos que tienen derecho a dirigirse mutuamente reivindicaciones de justicia» (Fraser, 2008, 42).

Se trata de la cuestión central del sujeto político y de la delimitación de los marcos de la justicia; marcos que dan sentido a las diferentes reivindicaciones de justicia. Propone un criterio de re-enmarque de las reivindicaciones de justicia: «el principio de todos los sujetos». Entendiendo por sujetos «todos aquellos que están sujetos a una estructura de gobernación determinada, están en posición moral de ser sujetos de justicia en relación con dicha estructura» (Fraser, 2008, 126). Se propone un principio o criterio de delimitación de las reivindicaciones de justicia que es reflexivo. Los marcos de la comunidad de la justicia/política no están predeterminados antes de los sujetos, sino que son estos mismos sujetos que al evaluar las condiciones e injusticias en que viven pueden reevaluar críticamente los marcos de la justicia hasta ahora vigentes. Una concepción antiesencialista y procedimentalista de la justicia que la conecta con la democracia. Los marcos de la justicia y la política serán aquellos que democrática, dialógica y antagónicamente vayan construyendo los propios sujetos de la comunidad política y de justicia.

La teoría de la justicia de Fraser combina un monismo normativo con una ontología pluralista de la justicia y de la injusticia. Esta teoría es aplicable a la cuestión que atañe aquí, sobre la justicia de la política del cuidado; es decir, la institucionalización material e ideológica de ciertas formas de cuidado. Se identifican diversas formas de justicia e injusticia de la política del cuidado. Todo cuidado o relación de cuidar será justa si y sólo si permite la «paridad de la participación», tanto del cuidador como del receptor del cuidado. Tanto el cuidador como el receptor, cuya distinción es lábil y contingente, han de tomarse como sujetos en igualdad de condiciones a la hora de participar en las formas del cuidar. Una forma de injusticia asociada a este principio de justicia es la que se da en aquellas formas del cuidar exclusivamente unidireccionales en que el cuidado va del cuidador al receptor y no se establece otra forma de retornar el cuidado recibido al cuidador. Aquí, entraría en escena la valorización de las formas alternativas del cuidado. Las relaciones de subordinación e infantilización del receptor del cuidado por parte tanto del cuidador como de la sociedad, también entrarían dentro del ámbito de esta forma de injusticia. En el fondo, la desautonomización moral del receptor del cuidado sería la base de dicha injusticia.

Siguiendo a Fraser, la paridad en la participación, sólo es posible con ciertas condiciones sociales tales como: la distribución, el reconocimiento y la representación. El cuidado o las

19 Armada con esta teoría bidimensional de la justicia, Fraser podrá llevar a término su manera de entender la teoría crítica, entendida ésta como un «programa de investigación y un marco conceptual con miras a los objetivos y actividades de aquellos movimientos sociales de oposición (...) utilizando categorías y modelos explicativos que revelen y no oculten las relaciones de dominación masculina y subordinación femenina» (Carbonero, M. A., Valdivieso, J., 2011, 332). Así, la teoría de la justicia se convierte en teoría critica, es decir en teoría social y política crítica con la realidad, atenta a los antagonismos subyacentes a la misma y a las diferentes alternativas de transformación emancipadora de la realidad. Una teoría de la justicia reevaluada y revisada a la luz del análisis de diferentes formas de injusticia que van emergiendo o produciéndose. 
formas del cuidar serán justos si parten y generan una distribución igualitaria de los recursos materiales y legales, un reconocimiento a dichas formas de relación y un marco estable y reflexivo de toma de decisión por parte tanto del cuidador como del receptor del cuidado. Dicho negativamente, las formas de cuidar que no generen o partan de iguales recursos materiales, que no se visibilicen y se valoren socialmente, o que no generen marcos de interacción entre los sujetos del cuidar, provocaran formas de injusticia del cuidar. En este sentido, la cuestión del quién o el marco de toma de decisión en las diferentes formas del cuidar son centrales para constituir un cuidado democrático. Sólo será justa aquella forma de cuidar en que tanto el cuidador como el receptor del cuidado pacten, acuerden y negocien las condiciones y límites del cuidar. Esta cuestión abre la vía a la necesaria democratización del cuidar, la cual está evidentemente condicionada por las dos condiciones sociales previas de la justicia del cuidar: que se garantice una distribución material de los recursos para las formas del cuidar equiparables a otras formas o tareas sociales y una valoración de dichas tareas y actividades al nivel de otras actividades socialmente valoradas y reconocidas ${ }^{20}$.

\section{A modo de conclusión: la ciudadanía que cuida y que se cuida}

El análisis de la realidad social y política desde la perspectiva del cuidado, como elemento central de la vida humana y las interacciones sociales, conduce a una crítica de la concepción hegemónica de la ciudadanía moderna. Una crítica que entronca directamente y se asociada con las críticas feministas a la misma, ya que el cuidado como actividad infravalorada e invisibilizada ha sido otorgado históricamente a las mujeres, como trabajo no productivo, no remunerado e incapaz de generar derechos de ciudadanía.

La ciudadanía moderna liberal capitalista entendida como una forma de presencia del individuo frente a la comunidad política (Peña, 2003, 216) que «confiere a los individuos un estatus formal haciendo abstracción de cualquier particularidad, marca o diferencia, sea de raza, clase, sexo o cualquier otra» (Agra, 2002,131) se basa en una cierta ontología social y política que invisibiliza tanto la desigualdad material que hay entre los diferentes

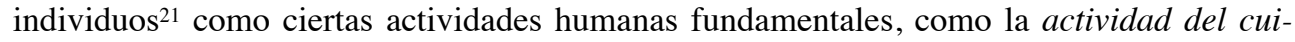
dado. Actividad, que como se ha visto, permite la reproducción social, la socialización de los individuos y su bienestar. Por ello, se puede hablar de límites de la ciudadanía moderna o críticas androcéntricas de la misma, ya que al centrarse en la igualdad formal de los individuos, oscurece como cuestión política fundamental quién y cómo son los individuos.

20 En España la aprobación de la Ley de la promoción de la autonomía personal y atención a las personas en situación de dependencia y a las familias, conocida como «Ley de dependencia», en 2006, constituye un paso en este sentido. No obstante se debe resaltar que con la crisis económica, los planes de reajuste económico y el ascenso al poder del partido conservador, el despliegue de la ley de la dependencia ha ido en retroceso. Señalar que la Asociación Estatal de Directores y Gerentes en Servicios sociales «acusó al Ministerio de Sanidad, que encabeza Ana Mato, de manipular en beneficio propio las cifras de la controvertida ley de la dependencia, que se diluye poco a poco entre la falta de recursos que ya sufría desde su entrada en vigor y los recortes del Gobierno que la están rematando de forma definitiva» (http:// www.directoressociales.com/noticias/301-mato,-acusada-de-falsear-la-ley-de-dependencia.html).

$21 \mathrm{Al}$ respecto, I. M. Young afirma que «Ciudadanía para todas las personas y para cada persona lo mismo en tanto que ciudadano/a. El moderno pensamiento político por lo general asumió que la universalidad de la ciudadanía, en el sentido de la ciudadanía para todas las personas, implica también una universalidad de la ciudadanía en el sentido de que estatus de ciudadano/a trasciende la particularidad y la diferencia» (Young, 1996, 99) 
La perspectiva feminista centrada en el cuidar ha mostrado la ficción interesada sobre la que se ha construido la ontología social y política de la ciudadanía moderna. Individuo que al convertirse en ciudadano, es decir, al otorgársele derechos, mecanismos de participación política en una determinada comunidad política y de identificación con dicha comunidad produce una concepción sesgada de la ciudadanía, que impide el igual acceso a la misma de aquellos seres y actividades que no se adapten a dicha abstracción fundante del individuo moderno ${ }^{22}$. La crítica a dicha abstracción fundante de la ciudadanía moderna capitalista abre la puerta a una nueva concepción de la ciudadanía sensible a las diferencias de género y a ciertas actividades marginadas socialmente. Importante mostrar que la conexión entre mujeres y cuidado, ha sido un constructo histórico e ideológico, socialmente «eficiente» para una determinada forma de organizar la producción y reproducción social. Una ciudadanía sensible con las diferencias de género no debe reintroducir el cuidado como actividad generizada. El cuidado ha sido una actividad despreciada e infravalorada socialmente y en el cual han sido históricamente socializadas las mujeres. No se trata de asociar acríticamente mujer y cuidado, sino en revalorizar socialmente el cuidado para construir una sociedad más igualitaria y más humana.

Una ciudadanía sensible con las diferencias de género no ha de renunciar a las actividades del cuidar sino que tiene que luchar por mostrar el error de su infravalorización e invisibilización. En el debate en torno a la ciudadanía feminista, las posiciones han pivotado entre dos extremos. Por una parte, las defensoras de una ciudadanía universalista que renuncian a las diferencias de género en pos de la igualdad, y por otra parte las defensoras de una ciudadanía diferenciada para conseguir una igualdad de género material, no simplemente formal ${ }^{23}$. La posición que defiende una extensión a las mujeres en clave universalista de la ciudadanía moderna y capitalista llevaría a las mujeres a un camino sin salida. Supondría la asimilación de las mujeres al varón y la adaptación de las mismas a un modelo e ideal de individuo y ciudadano alienado y deshumanizado, y como tal ficticio ${ }^{24}$. Alguien deberá continuar con las tareas que la mujer abandona para entrar en el reino de la ciudadanía masculina, socialmente despreciadas e infravaloradas, pero necesarias para mantener la reproducción de la propia sociedad. Una opción que no generaría una sociedad más igualitaria, sino que perpetuaría la desigualdad social, aunque ésta fuese transferida a otro colectivo o grupo social en base a criterios diferentes.

Por otro lado, la solución de una ciudadanía diferencial en razón de género corre el riesgo de estabilizar la diferenciación de género. Igualdad de género que no se conseguirá, ya que

22 En este punto, se puede entroncar con las críticas de Pateman a la teoría política moderna. Ella habla de contrato sexual previo al contrato social, que limita y condiciona el estatus de las mujeres en la sociedad civil. Aquí podríamos hablar de un contrato de cuidados, previo al contrato social, que imputa los cuidados a los individuos no libres en la sociedad civil, sean mujeres, esclavos, inmigrantes, etc.

23 Ésta es una caracterización simplista del debate feminista sobre la ciudadanía, ya que hay diferentes matizaciones dentro de las posiciones extremas, además de toda una pléyade de posiciones intermedias. En el caso de la primera posición encontramos a M. Nussbaum, y en el segundo a autoras como C. Pateman. Al respecto Pateman sostiene: «El feminismo persigue un orden social diferenciado dentro del cual las diversas dimensiones son distintas pero no separadas u opuestas, basado en una concepción social de la individualidad, que incluye a mujeres y hombres como seres biológicos diferenciados pero no como criaturas desiguales... Dadas las implicaciones sociales de las capacidades reproductivas de las mujeres, seguramente es utópico suponer que la tensión entre lo personal y lo político, entre amor y justicia, entre individualidad y comunalidad desaparecerá con el liberalismo patriarcal» (Pateman, 1996: 52)

24 Se trata del famoso dilema de M. Wollstonecraft que apuntaba C. Pateman (1995), donde las mujeres o se incorporan a la ciudadanía definida por el sujeto varón y dejan de ser mujeres, o renuncian a la ciudadanía para no asimilarse al varón. 
al estabilizar la diferenciación siempre será igualdad entre diferentes, corriendo el peligro de que esta diferencia se torne otra vez en desigualdad (al jerarquizarse). Desde la perspectiva del cuidado, la ciudadanía diferencial puede entender erróneamente el cuidado al haber sido histórica y socialmente imputado a las mujeres, como un elemento de diferenciación respecto del varón. Con lo cual se refuerza la generización del cuidado, impidiendo formas de cuidar justas, es decir, libremente elegidas y concertadas entre individuos independientemente de su género.

La perspectiva del cuidado abre una nueva vía para la conceptualización de una ciudadanía sensible con las diferencias de género. Una nueva vía que hace de la diferenciación de género un elemento central en su crítica a la ciudadanía moderna capitalista, y como tal, real históricamente y socialmente. Defiende que esta diferenciación no se convierta en algo pertinente en la construcción de una nueva ciudadanía sensible tanto a las diferencias de género como al valor e importancia que tiene el cuidado. Esta nueva ciudadanía estaría cercana a la propuesta de $\mathrm{Ch}$. Mouffe ${ }^{25}$. No se trata de despolitizar las relaciones entre los diferentes sexos, sino que éstas no se institucionalicen, provocando aquello que se quiere evitar; que se intensifiquen y se fijen.

Se aboga con Mouffe y a partir del análisis de la centralidad del cuidar por una nueva ciudadanía que se replantee la abstracción y ficción del individuo propietarista, independiente y egoísta moderno. Una nueva ciudadanía que contemple y valore las diferentes formas del cuidar y sea una nueva fuente de relaciones de reciprocidad y solidaridad. A partir de aquí se han de estructurar nuevas formas de derechos, pertenencias y participación política. Es una nueva forma de ciudadanía que integra tanto las críticas como las diferentes reivindicaciones feministas. Una ciudadanía más interesada en las virtudes ciudadanas, que no en los derechos individuales. Basada en una concepción democrático-radical tanto de la ciudadanía como del cuidar. Por tanto, una ciudadanía de raíz republicana ${ }^{26}$ y crítica con el modo de producción social capitalista.

25 Para ella «las limitaciones de la concepción moderna de la ciudadanía no van a superarse si en su definición se vuelve políticamente relevante la diferencia sexual, sino al construir una nueva concepción de ciudadanía en la que la diferencia sexual se convierta en algo efectivamente no pertinente» (Mouffe, 1993: 118)

26 En los estudios sobre la ciudadanía se habla de modelos o «tipos ideales» de ciudadanía. Se sostiene que existen tres modelos o concepciones de la ciudadanía: la liberal, la comunitarista y la republicana. Siendo muy sintéticos, podríamos decir que la concepción liberal se centra en la dimensión de los derechos y libertades (entendidas negativamente) de los miembros de la comunidad política. La concepción comunitarista se centra en la dimensión de la pertenencia. En el hecho de quién pertenece y quién no a la comunidad política, y cómo esta pertenencia marca la presencia y el estatus de los miembros de la comunidad política. La concepción republicana se centra en la dimensión participativa de la ciudadanía (tradición que arranca con Aristóteles, pasa por el renacimiento con el humanismo cívico y llega a la modernidad con los republicanos, tanto autoritarios como demócrata-radicales) o las libertades de los ciudadanos (entendidas positivamente). Si se sigue la historia del republicanismo moderno, sobre todo en su versión demócrata-radical que encarnan Robespierre y Marx, y que en cierta manera está presente en el movimiento obrero que se desarrolla a finales del siglo XIX, como ha expuesto A. Domènech en su obra El Eclipse de la fraternidad (2004), el cuidado de los otros siempre ha estado presente a través de instituciones tales como cajas de resistencia, mutualidades, casas de socorro, cajas de ahorro, etc. Así, la valorización del cuidado históricamente ha estado más relacionada con las concepciones republicanas de la ciudadanía. Además, teóricamente la concepción republicana preocupada no tanto por los derechos como por las virtudes del ciudadano que refuerzan su participación política, está más cercana a la valorización de los cuidados. No obstante, esto no quiere decir que el republicanismo, tanto histórico, como teóricamente sea sensible a la diferencia de género, ya que no ha sido ha así. El reto de una política feminista democrática seria aunar ambas sensibilidades. 


\section{Referencias}

Agra, M. X., «Ciudadanía: el debate feminista», en: F. Quesada (Ed.): Naturaleza y sentido de la ciudadanía hoy, Madrid, UNED, 2002, pp. 129-160.

Amorós, C., (a) «El feminismo como proyecto filosófico-político», en: F. Quesada (Ed.): Ciudad y Ciudadanía. Senderos contemporáneos de la filosofía política, Madrid, Trotta, 2008, pp. 69-85.

Amorós, C., (b) «El legado de la Ilustración: de las iguales a las idénticas», en: A. H. Puleo (Ed.): El reto de la igualdad de género. Nuevas perspectivas en Ética y Filosofía política, Madrid, Biblioteca Nueva, 2008, pp. 45-61.

Benhabib, S., El ser y el Otro en la ética contemporánea. Feminismo, comunitarismo y postmodernismo, Gedisa, Barcelona, 2006.

Carbonero, M. A., Valdivielso, J. (Eds.), Dilemas de la justicia en el siglo XXI. Género y Globalización de Nancy Fraser, Palma de Mallorca, Edicions UIB, 2011.

Carrasco, C., Borderías, C. y Torns, T., (Eds.), El trabajo de cuidados. Historia, teorías y políticas, Barcelona, Catarata, 2011.

Duran, A., «La nueva división del trabajo en el cuidado de la Salud», Política y Sociedad (Madrid), no 35, 2000, pp. 9-30.

Duran, A., «Dependiente y Cuidadores», Revista del Ministerio de trabajo e inmigración (Madrid), $\mathrm{n}^{\mathrm{O}}$ 60, 2006, pp. 57-74.

Gilligan, C., In a different Voice. Psycological theory and women's development, Harvard University Press, USA, 2003.

Mouffe, Ch., El retorno de lo político. Comunidad, ciudadanía, pluralismo, democracia radical, Paidós, Barcelona, 1999.

Mouffe, CH., En torno a lo político. F.C.E., Buenos Aires, 2007.

Comins, I., Filosofía del cuidar, Barcelona, Icaria, 2009.

Fraser, N., Escalas de justicia, Barcelona, Herder, 2008.

Fraser, N., y Gordon, L., «Contrato versus caridad: una reconstrucción de la relación entre ciudadanía civil y ciudadanía social», Isegoría (Madrid), nº 6, 1992, pp. 65-82.

López de la Vega, M. T., «Justicia y cuidado», en: A.H.Puleo (Ed.): El reto de la igualdad de género. Nuevas perspectivas en Ética y Filosofía política, Madrid, Biblioteca Nueva, 2008, pp. 241-253.

Pateman, C., El contrato sexual, Antropos, Madrid, 1995.

Pateman, C., «Críticas feministas a la dicotomía público/privado» en Castells, C. (Comp.), Perspectivas feministas en teoría política, Barcelona, Paidós, 1996, pp. 31-52.

Peña, J., «La ciudadanía», en: A. Arteta, E. García y R. Máiz (eds.): Teoría política: poder, moral y democracia, Madrid, Alianza Editorial, 2003, pp. 215-245.

Thomas, C., «Deconstruyendo los conceptos de cuidados» en Carrasco, C., Borderías, C. y Torns, T., (Eds.), El trabajo de cuidados. Historia, teorías y políticas, Barcelona, Catarata, 2011.

Tronto, J., «Cuando la ciudadanía se cuida: una paradoja neoliberal del bienestar y la desigualdad» en: Instituto Vasco de la Mujer (Ed.); Congreso Internacional Sare 2003: «Cuidar cuesta: costes y beneficios del cuidado, País Vasco, Instituto Vasco de la Mujer, 2004, pp. 232-253.

Young, I.M., «Vida política y diferencia de grupo: una crítica del ideal de ciudadanía universal» en Castells, C. (Comp.), Perspectivas feministas en teoría política, Barcelona, Paidós, 1996, pp. 99-126. 